\title{
Mid Trimester Missed Abortion Termination Using Intravaginal Misoprostol - A Prospective Study In DMCH
}

\author{
SHARMEEN MAHMOOD ${ }^{1}$, SADIAAFRIN $^{2}$, FARHANA DEWAN ${ }^{3}$
}

\begin{abstract}
Objectives: The objective of the study was to find out the efficacy and safety of misoprostol in termination of missed abortion.

Materials and Methods: This was a prospective study carried out during the time from August 2009 to April2010 in Dhaka Medical College Hospital.

Results: A total 50 cases of missed abortion (12-28weeks) were included in the study. Tab.misoprostol(2oo $\mu \mathrm{gm})$ was used pervaginally 4 hourly for termination of pregnancy.Maximum 4 tab. were used. Outcome variables were doses of misoprostol, expulsion times need for use of oxytocin and $D$ and $C$ and side effect of misoprostol. In the present study, 58\% percent (29 out of 50 ) experienced complete expulsion (20\% after $1^{\text {st }}$ dose, $24 \%$ after $2^{\text {nd }}$ dose $24 \%$ after $3^{\text {rd }}$ doseand,31\%after4th dose).24\% cases needed oxytocin drip as an adjunct and 18\% needed surgical evacuation when 4 doses of misoprostol (tab cytomis)and oxytocin fail to expel the product of conception. Mean ( $\pm S D$ ) time required for expulsion of product of conception was $11.44 \pm 4.43$ hours in 29 (58\%) women who were given tab misoprostol only. The results showed that 5(out of 25) has a complete expulsion after first dose, 13 after second 4 after $3^{\text {rd }}$ and Mean induction expulsion time was 6.1 hours The most common complication was temperature $6 \%$, vomiting $4 \%$, and diarrhoea $2 \%$.
\end{abstract}

Conclusion: Vaginal application of misoprostol can be used to women with missed abortion for complete expulsion of the product of conception and may reduce the need for surgical intervention.

Introduction:

More than $50 \%$ of human pregnancies may be lost $^{1}$, although in only $15 \%$ in this perceived as miscarriage ${ }^{2}$, with lower abdominal cramp and uterine bleeding being the presenting symptoms of threatened/inevitable abortion. An increasing proportion of these unsuccessful pregnancies is now diagnosed on routine ultrasound scanning and designated as mid trimester abortion. This terminology has been questioned recently3 but the term is still widely used and accepted by practicing clinicians. The word "mid trimester missed abortion " does not refer to the failure of the gynaecologist to diagnose the condition3, but to the missing uterine force which have failed to expel non viable product of conception.

The standard treatment of mid trimester missed abortion used to be surgical evacuation of the uterus 4 but expected management or medical treatment are becoming reasonable alternatives. Medical treatment commonly consists of administration of misoprostol to induce uterine contraction and expulsion of product of conception. The administration of misoprostol is invariably oral, but different prostaglandins may be given in different ways-parentral, oral or local (intravaginal). Studies have demonstrated that the vaginal administration of misoprostol may be superfluous, as progesterone levels are in range of the luteal phase 5 (ie, lower than in viable pregnancies). Therefore a trial was designed to treat women with missed abortion by vaginal administration of misoprostol.

When decision for termination of pregnancy is taken, the safe effective method has long been a challenge.

1. Assistant Professor, Department of Obst and Gynae, Shaheed Suhurawardy Medical College (SHSMC)

2. OSD, DGHS

3. Professor of Obst and Gynae, SHSMC 
Currently a more interventional route is usually undertaken, with the uterus being evacuated soon after diagnosis. In the first trimester this is usually done by suction curettage, where as in the second trimester the uterus is generally quiescent and non responsive and at this stage termination by suction curettage is more traumatic than that in early pregnancy and complications are more common and may be more severe. In mid 1950s synthetic oxytocin was available and increasing doses were used to terminate mid trimester abortion. But in early 1980s, the local administration of prostaglandins were studied and the results were very promising. In clinically recognized pregnancies, spontaneous abortion occurs in 15\% of cases. The rate is much higher for preclinical pregnancies. Diagnosis is much more frequent because of early use of ultrasonography.

Medical reports of the year 2008 and 2009, there were $147(0.7 \%) \& 175(0.6 \%)$ cases of missed abortions admitted in Dhaka medical college Hospital respectively.

Misoprostol is $90 \%-100 \%$ effective when used for missed abortion in women with gestational age 12-28 weeks. A majority of cases have the expulsion within 48 hours at a dose of 200 microgram vaginal every 12 hours until expulsion or 400 microgram orally every 4 hours until expulsion. ${ }^{6}$ If misoprostol proves safe and effective, a large number of patient will be benefited and will escape from surgical intervention and complication. ${ }^{5}$ The present study was done to find out the efficacy of vaginal misoprostol for safe termination of mid trimester missed abortion.

\section{Materials and Methods:}

This was a prospective cross sectional study done in Obstetric and Gynaecology department of Dhaka Medical College Hospital (DMCH) over a period of nine months from August 2009 to April 2010.During this period all admitted cases of missed abortion within 12 to 28 weeks of gestational age, 50 cases were selected for the present study.

Only clinically diagnosed and ultrasonographically confirmed cases of mid trimester missed abortion were included for this study.

Patients with known hypersensitivity to prostaglandins and women having previous history of caesarian section were excluded from this study.

After taking detailed history and performing examination, an USG was done which is an integral part of diagnosis for missed abortion. After taking written informed consent Tab. Misoprostol (Marketed as Cytomis) 1 tab = 200 microgram was introduced per vagina and applied in the posterior fornix. The doses were repeated every four hours for a total of 4 doses or until expulsion of the gestational sac, which one come earlier. Follow up was given at four hour interval or whenever the patient complaints of any problem. If the patient did not respond, then decision for other methods- like oxytocin induction or Foleys catheter or surgical evacuation was taken. An USG was done after 24 hours of expulsion to confirm complete abortion. Collected data were analyzed in SPSS.

\section{Results:}

Study population showed the age range was $17-40$ years where the mean age was $23.6 \pm 6.06$ (Table- I). It also showed the parity range covered primi upto $4^{\text {th }}$ gravida with mean $( \pm S D$ ) was $1.22 \pm 1.28$ (range $0-4$ ) (Table- I). Most of the patients (56\%) belonged to average socio economic status. Study population showed mean ( $\pm S D$ ) gestation age of the women was 20.06 \pm 4.81 weeks (range 13-28 weeks). Seventeen (34\%) cases belong to 13-16 weeks, 7 (14\%) belong to $17-20$ weeks, 13 (26\%) belong to $21-24$ weeks, 13 (26\%) belong to $25-28$ weeks gestation age. In this study, 29(58\%) women required only tab misoprostol for expulsion of gestational sac and 12 (24\%) women required oxytocin drip additionally. However the rest 9 (18\%) women required (D\&C) when Tab misoprostol and oxytocin drip failed to expel the gestational sac completely. Table-II. Mean ( $\pm S D$ ) time required for expulsion of product of conception was $11.44 \pm 4.43$ hours in 29 women who were given Tab misoprostol only, 20.13 \pm 1.25 hours in 12 women who were given Tab misoprostol followed by oxytocin drip, and $21.29 \pm 0.99$ hours in 9 women who required $D \& C$ when Tab misoprostol and oxytocin drip failed to expel the product of conception completely (Table - III). Vaginal misoprostol treatment appeared to be well tolerated. Out of 10 patients with minor complaints, only 1 patient showed significant gastrointestinal side - effect, e.g. diarrhoea. None of the patients developed any major complications like- excessive haemorrhage, perforation, rupture, coagulopathy etc (Table - IV). Table- $V$ shows that complete expulsion of product of conception was achieved by only misoprostol in 29 (58\%) cases, by misoprostol plus oxytocin in $9(18 \%)$ cases and by misoprostol plus oxytocin plus 
D\&C in 9 (18\%) cases. In 3 (6\%) cases, misoprostol + oxytocin resulted in incomplete expulsion and then they were completed by D\&C. Only Tab cytomis was required in maximum number of women in gestational age group 21-24 weeks (76.9\%) and 25-28 weeks (69.23\%), Tab cytomis and oxytocin drip were used in maximum 2(15.38\%) women in gestational age group 21-24 weeks, and surgery was required in maximum number of women in gestational age group 13 -16 weeks (29.42\%). Table- VI revealed that majority of the patients beyond $20 \mathrm{wks}$ responded to only vaginal misoprostol therapy. Oxytocin adjunct is needed where gestational age is below 20wks in 8 patients. Similarly 5 patients required D\&C where gestational age is $12-16$ wks. So misoprostol was found more effective in advanced gestational age.

Table-I

Data of the study population $(n=50)$

\begin{tabular}{|c|c|c|c|c|}
\hline Parameters & No. of patients & Percentage & Range & Mean $\pm S D$ \\
\hline \multicolumn{5}{|l|}{ Age in years } \\
\hline$\leq 20$ & 11 & $22 \%$ & $17-40$ years & $23.6 \pm 6.06$ \\
\hline $21-30$ & 35 & $70 \%$ & & \\
\hline e"31 & 04 & $08 \%$ & & \\
\hline \multicolumn{5}{|l|}{ Parity } \\
\hline 0 & 14 & $28 \%$ & $0-4$ years & $1.22 \pm 1.28$ \\
\hline 1 & 17 & $34 \%$ & & \\
\hline 2 & 15 & $30 \%$ & & \\
\hline 3 & 02 & $04 \%$ & & \\
\hline 4 & 02 & $04 \%$ & & \\
\hline \multicolumn{5}{|c|}{ Socio-economic condition } \\
\hline Low & 15 & $30 \%$ & & \\
\hline Average & 28 & $56 \%$ & & \\
\hline High & 07 & $14 \%$ & & \\
\hline \multicolumn{5}{|c|}{ Weeks of gestational } \\
\hline 13-16 & 17 & $34 \%$ & 13-28 weeks & $20.06 \pm 4.81$ \\
\hline $17-20$ & 07 & $14 \%$ & & \\
\hline $21-24$ & 13 & $26 \%$ & & \\
\hline $25-28$ & 13 & $26 \%$ & & \\
\hline
\end{tabular}

Table-II

Procedure required for expulsion of gestational sac

\begin{tabular}{lcc}
\hline Procedure & Number of patients & Percentage (\%) \\
\hline Tab misoprostol only & 29 & 58.0 \\
Doses required: & 6 & \\
1 & 7 & 20.6 \\
2 & 7 & 24.14 \\
3 & 9 & 24.14 \\
4 & 12 & 31.03 \\
Tab misoprostol followed by oxytocin drip & 9 & 24.0 \\
Tab misoprostol followed by oxytocin drip and then & & 18.0 \\
surgical evacuation (D\&C) & \\
\hline
\end{tabular}


Table- III

Induction-expulsion interval in relation to mode of induction

\begin{tabular}{lccc}
\hline Induction & No. & \multicolumn{2}{c}{ Expulsion time (hours) } \\
\cline { 3 - 4 } & & Range & Mean \pm SD \\
\hline Tab. Misoprostol & 29 & $3.00-19.50$ & $11.44 \pm 4.43$ \\
Tab. Misoprostol+ Oxytocin drip & 12 & $19.00-22.00$ & $20.13 \pm 1.25$ \\
Tab. Misoprostol+ Oxytocin drip+D\&C & 9 & $20.00-22.00$ & $21.29 \pm 0.99$ \\
\hline
\end{tabular}

Table- IV

Side effects

\begin{tabular}{lcc}
\hline Side effects & Number of patients & Percentage (\%) \\
\hline Nausea & 4 & 8.0 \\
Fever & 3 & 6.0 \\
Vomiting & 2 & 4.0 \\
Diarrhoea & 1 & 2.0 \\
No side effects & 40 & 80.0 \\
\hline
\end{tabular}

Table- V

Ultrasonographic evaluation after expulsion of product of conception

\begin{tabular}{lccccc}
\hline Results & \multicolumn{2}{c}{ Complete expulsion } & & \multicolumn{2}{c}{ Incomplete expulsion } \\
\cline { 2 - 3 } & No. of patients & Percentage & & No. of patients & Percentage \\
\hline Tab. Misoprostol & 29 & $58 \%$ & & 0 & $0 \%$ \\
Tab. Misoprostol+ Oxytocin drip & 9 & $18 \%$ & & 3 & $6 \%$ \\
Tab. Misoprostol+ Oxytocin drip+ D\&C & 9 & $18 \%$ & & 0 & $0 \%$ \\
\hline
\end{tabular}

Table-VI

Relationship between gestational age and mode of induction

\begin{tabular}{|c|c|c|c|c|c|c|c|}
\hline \multirow[t]{2}{*}{ Gestation (weeks) } & \multirow[t]{2}{*}{ No. } & \multicolumn{2}{|c|}{ Misoprostol } & \multicolumn{2}{|c|}{$\begin{array}{c}\text { Tab. Misoprostol+ } \\
\text { Oxytocin drip }\end{array}$} & \multicolumn{2}{|c|}{$\begin{array}{l}\text { Tab. Misoprostol+ } \\
\text { Oxytocin drip+ D\&C }\end{array}$} \\
\hline & & No. & $\%$ & No. & $\%$ & No. & $\%$ \\
\hline $13-16$ & 17 & 7 & 41.18 & 5 & 29.41 & 5 & 29.41 \\
\hline $17-20$ & 7 & 3 & 42.86 & 3 & 42.85 & 1 & 14.28 \\
\hline $21-24$ & 13 & 10 & 76.92 & 2 & 15.38 & 1 & 7.69 \\
\hline $25-28$ & 13 & 9 & 69.23 & 2 & 15.38 & 2 & 15.38 \\
\hline
\end{tabular}

\section{Discussion:}

Missed abortion is a common complication of early pregnancy, occurring in upto 15 percent of all clinically recognised pregnancies. ${ }^{7}$ The majority of cases are currently treated by dilatation and curettage (D\&C). The rationale that all spontaneous abortions should be treated with $D \& C$ to prevent infection and haemorrhage has been questioned. ${ }^{8}$
Treatment of incomplete abortion with misoprostol has also been reported with varying degree of success. ${ }^{9,10}$ With the rising use of early ultrasound, an increasing number of miscarriages present as missed abortions before the onset of cramping and bleeding. A small case series reported that seven of eight women with missed abortion had a complete abortion after treatment with vaginal misoprostol compared with three of 12 treated by oral route. ${ }^{11}$ 
This study was carried out to find out the efficacy of this new drug (misoprostol) in the expulsion of product of conception with special attention to number of doses required and induction-expulsion interval and need for additional oxytocin/surgical evacuation.

In a study coducted by Zalanyi using vaginal misoprostol for missed abortion,on women having gravidity $2.4 \pm 1.42$ and parity $1.0 \pm 0.84$. The study included only cases of amenorrhoea of upto 13 weeks, where as, our study included mid-trimester cases. ${ }^{12}$

The efficacy of vaginal misoprostol was also studied for medical management of missed abortion by Wood $^{13}$, where gestational age of the patients ranged from 7-17 weeks (median 12 weeks)and 56 percent of the patients were nulliparous. ${ }^{13}$

In both the above studies, vaginal misoprostol was found to be quite effective in expulsion of production of conception in missed abortion cases, reducing the need for surgical evacuation.

In the present study, 58 percent (29 out of 50) experienced complete expulsion (20\% after $1^{\text {st }}$ dose, $24 \%$ after $2^{\text {nd }}$ dose, $24 \%$ after $3^{\text {rd }}$ dose, 31\% after $4^{\text {th }}$ dose). Twenty four percent cases needed oxytocin drip as an adjunct and 18percent needed surgical evacuation when four doses of misoprostol (tab cytomis) and oxytocin failed to expel the product of conception.

Mean $( \pm S D)$ time required for expulsion of product of conception was $11.44 \pm 4.43$ hours in 29 (58\%) women who were given Tab misoprostol only. In others, the time was much higher. The side effects experienced by the patients were negligible, only two patients (4\%) had gastrointestinal cramps and diarrhoea, 3(6\%) patents experienced febrile reaction and 4(8\%) patients complained of nausea. Only $7(14 \%)$ cases who needed surgical evacuation.

In a study conducted by Zalanyi (Hungary), misoprostol $200 \mu \mathrm{g}$ was used vaginally for expulsion of product of conception in missed abortion. ${ }^{14}$ The results showed that 5 (out of 25) has a complete expulsion after $1^{\text {st }}$ dose, 13 after second, 4 after third and the mean induction-expulsion time was 6.1 hours (calculated only for successful cases). Three patients did not abort even after four doses, who required surgical evacuation of the uterus. There was no febrile complications. ${ }^{14}$

In a study carried out by Wood, 80 percent subjects aborted completely after two vaginal doses of $800 \mu \mathrm{g}$ of misoprostol tablet. It may be noted that dose used was quite high in comparison to the present study. In that study, there was also an additional benefit of having soft dilated cervix found during surgical treatment.

In a study by Refacy et al. it was found that vaginal misoprostol administration was more effective than the oral route. The local effect of misoprostol on the the cervix was considered to be one of the reason. ${ }^{15}$

In a study carried out in Bangladesh by Barua, using two tablets of misoprostol vaginaly, it was found that 60. 71 percent patients had complete expulsion with vaginal misoprostol, and among these, 42.85 percent patients responded with $1^{\text {st }}$ dose of $400 \mu \mathrm{g}$ of misoprostol, mean $( \pm S D)$ induction-expulsion time being $8.30 \pm 2.53$ hours. Only one patient (out of 56) experienced shivering as a complication and (out of 56) developed severe bleeding. ${ }^{16}$

This study showed that complete expulsion was more in patients with higher gestational age (21-24weeks). Patients who were of $13-16$ weeks gestational age needed more surgical evacuation.

In this study, a number of patients needed surgical evacuation, but one of the important observations is that in this case cervix was very soft and somewhat dilated during evacuation which reduced requirement of dilatation and less use of analgesics.

In this study no life threatening complications were observed like massive haemorrhage, perforation, spontaneous rupture, coagulopathy etc.

\section{Conclusion:}

Obstreticians/gynaecologists have recently been challenged to rethink their approach to miscarriage. Furthermore, the high success rates (more than 90\%) in the medical therapeutic abortion also suggest that non-surgical treatment should be considered.

From this small study, it is anticipated that medical management of missed abortion with vaginal misoprostol will prove to be a good alternative to surgical evacuation.

\section{References:}

1. Blanchard K, Winikoff B and Ellertson C, Oral and vaginal misoprostol to manage delivery in cases of foetal death.Obstet Gynecol,2009,50-3.

2. Goldberg AB,Carusi DA, Meckstroth KR Misoprostol in Gynonecolog, Current women's Health Reports 2008-3-475-83 
3. Certain MD. Schwartz JL, Guido RS. Early pregnancy failure current management concept.Obstet Gynacol Surve , 2006;56-10513

4. Blanchard K, Clark S, Winikoff B.Mmisoprostol for women's health ; a review. Obstate Gynaecol.2009.99;316-32.

5. Graudzinskas JG. Miscarriage, ectopic pregnancy and trophoblastic disease. In ; Edmondds DK, Editor dewhurst's Text book of obstetrics and gynaecology for post garaduats ,6 th ed.Bath; Blackwell Science Ltd. 2007;6175.

6. Ratanam SS, Bhasker k, Arulkumaran S, Prostaglandins. In : obstetrics and Gynaecology for prost graduates, Vol $1,2^{\text {nd }}$ ed.Orient Langman,2006;161-82

7. Daya S. Habitual abortion. In: Copeland LJ, editor.Textbook of gynaecology. Philadelphia: WB Saunders Company, 2000: 227-71.

8. Auco H, Ballagh S, Herris HA, Demasio k. Is curettage needed for uncomplicated incomplete spontaneous abortion? Am J Obstet Gynaecol 1998; 179:1279-82.

9. Chung TKH, Cheung LP, Leung TY, Haines CJ, Chang AMZ. Misoprostol in the management of spontaneous abortion. $\mathrm{Br} \mathrm{J}$ Obstet Gynaecol 1995; 102: 832-5.

10. de Long EM, Makin JD, Manefeldt E, De Wet $\mathrm{GH}$, Pattinson RC. Randomised trial of medical evacuation and surgical curettage for incomplete miscarriage. Br Med J 1995; 311:662.

11. Crcinin M, Moyer R, Guido R. Misoprostol for medical evacuation of early pregnancy failure. Obstet Gynaecol 1997; 89:768-72.

12. Zalanyi S. Vaginal misoprostol alone is effective in the treatment of missed abortion. $\mathrm{Br} \mathrm{J}$ Obstet Gynaecol 1998; 105: 1026-8.

13. Wood SL, Brain PH. Medical management of missed abortion: a randomized clinical trial. Obstet Gynaecol 2002; 99:563-6.

14. El Rafaey H, Calder L, Wheatly DN. Cervical priming with prostaglandin E1 analogue misoprostol and gemeprost. Lancet 1994;343:1207-9.

15. El Rafaey H, Rajasekar D, Abdalla M. Induction of abortion with mifepristone (RU486) and oral or vaginal misoprostol. N Engl J Med 1995; 332:983-7.

16. Barua S. Use of misoprostol in missed abortion [dissertation]. Dhaka: Bangladesh College of Physicians and Surgeons, 2003. 